East African Medical Journal Vol. 77 No. 7 July 2000

VENTRICULOPERITONEAL SHUNT SURGERY AND SHUNT INFECTIONS IN CHILDREN WITH NON-TUMOUR HYDROCEPHALUS AT THE KENYATTA NATIONAL HOSPITAL, NAIROBI

N.J.M. Mwang'ombe, MMed, PhD (Lond), Senior Lecturer and T. Omulo, MBChB, MMed, Lecturer, Department of Surgery, College of Health Sciences, University of Nairobi. P.O. Box 19676, Nairobi, Kenya

Request for reprints to: Dr. N.J.M. Mwang'ombe, Department of Surgery, College of Health Sciences, University of Nairobi. P.O. Box 19676, Nairobi, Kenya

\title{
VENTRICULOPERITONEAL SHUNT SURGERY AND SHUNT INFECTIONS IN CHILDREN WITH NON-TUMOUR HYDROCEPHALUS AT THE KENYATTA NATIONAL HOSPITAL, NAIROBI.
}

\author{
N.J.M. MWANG'OMBE and T. OMULO
}

\begin{abstract}
Objective: To study infections complicating ventriculoperitoneal (VP) shunt surgery in children with non-tumour hydrocephalus at the Kenyatta National Hospital, Nairobi.

Design: A retrospective survey.

Setting: Kenyatta National Hospital, Nairobi between January 1982 and December 1991. Subjects: Three hundred and forty five patients who underwent V-P shunt placement for non-tumour hydrocephalus.

Results: Three hundred and forty five patients underwent V-P shunt placement for nontumour hydrocephalus. There were 107 infection episodes involving 85 patients. The ages of these patients ranged from three months to 12 years. Most of the patients had congenital hydrocephalus. The infection rate was high $(\mathbf{2 4 . 6 \%})$ although comparable to infection rates reported for clean surgery in the hospital. Fever, septic wounds and features of shunt malfunction were the main presenting features. Bacteriological studies confirmed Staphylococcus aureus and coagulase negative staphylococci as the two most commonly isolated micro-organisms.

Conclusion: This study emphasises need to reduce infection rate in ventriculoperitoneal shunt surgery at the Kenyatta National Hospital. Definitive surgical treatment for hydrocephalus was in most cases delayed and this problem was also observed during revision of infected shunts. Late presentation was often due to ignorance and the fact that many patients went for traditional forms of treatment first before going to hospital.
\end{abstract}

\section{INTRODUCTION}

Hydrocephalus may be defined as the excess accumulation of cerebrospinal fluid within the cerebral ventricles due to a disturbance of its secretion, flow or absorption. Cerebrospinal fluid (CSF) is produced by the choroid plexus of the two lateral, the third and fourth ventricles though some may be formed on the surface of the brain and spinal cord (1). CSF circulates through the ventricles and subarachnoid space that surround both the brain and spinal cord. The two lateral ventricles communicate with the third ventricles through the foramina of Monro, which communicates with the fourth ventricles by means of the aqueduct of Sylvius. The CSF reaches the basal cisterns and subarachnoid space from the fourth ventricle through the lateral foramina of Luschka and foramen of Magendie. From these basal cisterns, CSF migrates over the convexities toward the cerebral sinuses where it is re absorbed into circulation by the arachnoid villi $(1,2)$.

Hydrocephalus may result from congenital or acquired causes which may disturb its secretion (for example: choroid plexus papilloma), its flow or its absorption. Hydrocephalus has also been classified as obstructive or non- obstructive. Obstructive hydrocephalus occurs where there is a block to the flow of CSF. Non-obstructive hydrocephalus occurs where there is free flow of the CSF along its pathway from the ventricles to the absorption area by arachnoid villi.

Hydrocephalus in children, if untreated, causes developmental disorders, mental deficiencies and shortened life expectancy in addition to blindness and other neurological deficits as a result of cerebral injury due to distention of brain tissue (3).

In this paper the results of a ten year retrospective study done to review the problem of V-P shunt infection at Kenyatta National Hospital between 1982 and 1991 are presented.

\section{MATERIALS AND METHODS}

This is a ten-year retrospective study from January 1982 to December 1991. The study includes patients aged one day old to 12 years managed for ventriculoperitoneal shunt infections at Kenyatta National Hospital. Patients with shunts for 
hydrocephalus due to tumours were excluded. The relevant data was obtained from the patients case notes in the hospital records department.

\section{RESULTS}

Three hundred and forty five patients underwent V-P shunt placement at Kenyatta National Hospital between January 1982 and December 1991. Eighty five of these patients developed VP shunt infections (24.6\% infection rate).

It was noted that some patients presented more than once during this period with what was seen to be different infections (initial infection having been considered treated). The majority of patients (78.8\%), however had only one infection episode each. Fourteen patients $(16.5 \%)$ presented two times with infection and four patients $(4.7 \%)$ presented three times. Therefore, there were 107 infection episodes involving 85 patients during that ten-year period (Table 1). There were forty eight male patients $(56.5 \%)$ and 37 female patients $(43.5 \%)$ giving a male: female ratio of 1.3:1.

The youngest patient was three months old and the oldest twelve years. Majority of the patients were below one year of age $(50.6 \%)$ as shown in Table 1 . There was a considerable delay from the time the patient was diagnosed to have hydrocephalus to the time of placement of a VP shunt. This time interval was less than three months in $43.5 \%$ of the patients (Fig. 1). The delay encountered in placement of VP shunt was usually due to unwillingness of parents of the patients to have a V-P shunt inserted or inability to afford the shunt.

Table 1

Pre-infection shunt revisions, age distribution in shunt infections and frequency of infection episodes

\begin{tabular}{|c|c|c|c|c|}
\hline & & Frequency & $\%$ & Total \\
\hline \multicolumn{2}{|l|}{ Shunt block } & 20 & 52.6 & \\
\hline \multirow{2}{*}{\multicolumn{2}{|c|}{$\begin{array}{l}\text { Shunt } \\
\text { migration }\end{array}$}} & 5 & 13.2 & \\
\hline & & & & \\
\hline \multicolumn{2}{|l|}{ Exposed shunt } & 5 & 13.2 & $38(100 \%)$ \\
\hline \multicolumn{5}{|l|}{ Shortening of } \\
\hline \multicolumn{2}{|l|}{ shunt } & 1 & 2.6 & \\
\hline \multicolumn{5}{|l|}{ Combination of } \\
\hline \multicolumn{2}{|l|}{ above } & 7 & 18.4 & \\
\hline \multirow{5}{*}{$\begin{array}{l}\text { Age distribution } \\
\text { in shunt infections }\end{array}$} & Less than & 43 & 50.6 & \\
\hline & one year & & & \\
\hline & $1-2$ years & 27 & 32.7 & $85(100 \%)$ \\
\hline & 3-6years & 8 & 9.4 & \\
\hline & $7-12$ years & 7 & 8.3 & \\
\hline \multirow{3}{*}{$\begin{array}{l}\text { Number of infection } \\
\text { episodes per patient }\end{array}$} & 1 & 67 & 78.8 & $85(100 \%)$ \\
\hline & 2 & 14 (28) & 16.5 & (107 \\
\hline & 3 & 4 (12) & 4.7 & episodes) \\
\hline
\end{tabular}

Figure 1

Time interval from onset of hydrocephalus to first shunt surgery

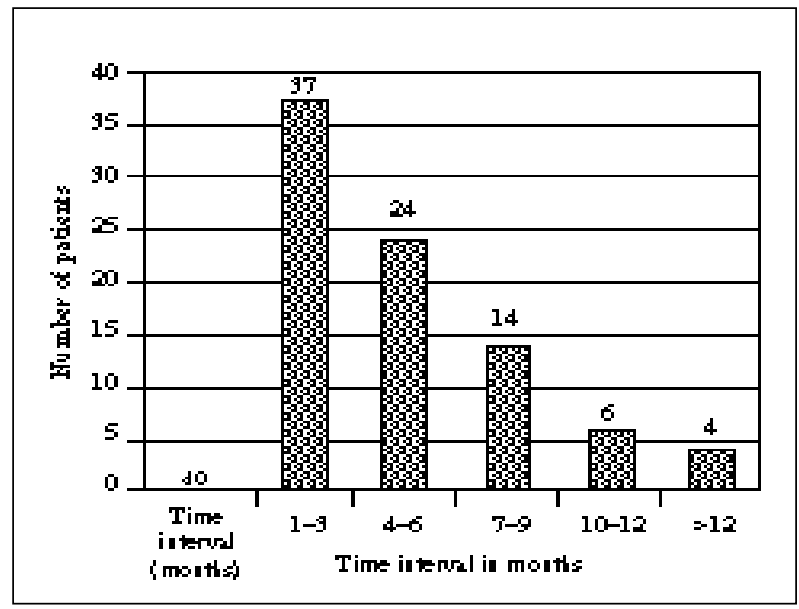

The causes of hydrocephalus were congenital in $77.6 \%$ of the patients and acquired in $22.4 \%$. Twenty seven patients $(31.8 \%)$ underwent shunt revisions for other reasons before they presented with shunt infection while 58 patients $(68.2 \%)$ had not undergone any previous shunt revisions. Eighteen of the patients had one shunt revision each, seven had two shunt revisions each, and two had three shunt revisions each giving a total of 38 shunt revisions. There were various reasons for these shunt revisions(Table 1) but shunt block was the most common reason.

Other local or systemic infections were observed in $21.3 \%$ of patients with V-P shunt infection. Thirteen patients were found to be anaemic and malnourished. Most of the infection episodes ( 83 out of the 107 episodes) presented within four months from the time of the last surgical procedure. Twenty of the infection episodes occurred between five and twenty months and only four infection episodes occurred after two years from the time of the last surgical procedure.

Fever, irritability and vomiting were the most common symptoms in patients who developed shunt infection. Fever was observed in 86 infection episodes. Irritability and vomiting were each found in 63 infection episodes. Other features observed were convulsions, lethargy, anorexia, dehydration and diarrhoea.

Thirty seven of the 107 infection episodes (34.6\%) were not associated with any wound at the site of previous shunt surgery while 70 infection episodes $(65.4 \%)$ had septic wounds. Of those with septic wounds, $59.3 \%$ had infections involving the abdominal wall, $26.7 \%$ were on the scalp, and $14.0 \%$ were found at other sites along the shunt tract. Features of shunt tract inflammation characterised by presence of redness and/or tenderness along the shunt tract were observed in 33 of the 107 infection episodes (Table 2). The shunt was found exposed in the wound in 25 of the 107 infection episodes. CSF leak through the wound was observed in 28 of the 107 infection 
episodes whereas swelling and cyst (or pseudocyst) formations along the shunt tract in form of subcutaneous CSF collections were seen in 35 infection episodes (Table 2).

Table 2

Signs and symptoms associated with shunt infections.

\begin{tabular}{lc}
\hline Symptom/sign & No. of infection episodes \\
\hline Fever & 86 \\
Irritability & 63 \\
Vomiting & 63 \\
Convulsions & 34 \\
Lethargy & 33 \\
Anorexia & 25 \\
Dehydration & 10 \\
Diarrhoea & 8 \\
Septic wound & 70 \\
Inflammation along shunt tract & 33 \\
Exposed shunt & 25 \\
Swelling and cysts along shunt & 35 \\
Tract & \\
CSF leaks & 28 \\
\hline
\end{tabular}

Signs of shunt block such as tense or bulging anterior fontanelle, progressive enlargement of the head, vomiting and convulsions were seen in 23 of the 107 infection episodes $(21.5 \%)$. Features suggestive of meningitis, such as neck stiffness and positive Kernig, were seen in 20 of the 107 infection episodes (18.7\%), while ventriculitis was found in three infection episodes $(2.8 \%)$ and peritonitis in eleven infection episodes $(10.3 \%)$.

Fifty six of the 107 infection episodes had bacteriological studies such as wound swabs, CSF culture and V-P shunt system culture done to determine culture and sensitivity pattern of the organisms. There were 43 wound swabs processed out of which 34 had bacteria isolated $(79.1 \%)$. There were $29 \mathrm{CSF}$ specimen processed, out of which eight were positive (27.6\%). Eight removed $\mathrm{V}-\mathrm{P}$ shunts were sent for culture and six grew organisms (75.0\%).

The spectrum of bacterial isolates and their source was also analysed. Staphylococcus aureus was the most commonly isolated microorganism (27 isolates) forming $48.2 \%$ of the total isolates. Coagulase negative staphylococci were the next most common isolates (nine isolates) forming $16.1 \%$ of the total isolates. Escherichia coli and citrobacter species were found in $7.1 \%$ of the total isolates (four isolates each). The other bacteria isolated were Klebsiella species (three), Acinetobacter (two), Pseudomonas species (two), Streptococcus faecalis (two), Salmonella typhimurium (one), Proteus species (one), and alpha-haemolytic streptococci (one).

Staphylococcus aureus was found to be sensitive to chloramphenicol (88.9\%), methicillin (75\%), erythromycin $(73.7 \%)$ and lincomycin $(86.7 \%)$. Sensitivity was low to some commonly used antibiotics such as penicillin (13.3\%), cotrimoxazole $(50 \%)$ and ampicillin $(26.7 \%)$. Coagulase negative staphylococci (the next commonest isolate) was found sensitive to chloramphenicol $(75 \%)$, penicillin (66.7\%) and amoxycillin (75\%).

Several management options were applied in treating patients with shunt infection. In 64 of the 107 infection episodes, the infected shunts were removed and reinsertion of a shunt done at a later date after the infection was treated. The time interval between removal of an infected shunt and reinsertion of new shunt varied between seven days and four weeks. In thirty out of the 107 infection episodes, the shunts were not removed but the patients were treated with systemic antibiotics. In five out of the 107 infection episodes, the shunts were removed and a new shunt inserted at the same sitting on the opposite side. In seven of the 107 infection episodes new shunts were inserted on opposite side with the old shunt still in place and the patients treated with systemic antibiotics The old shunts were removed at a later date, usually on the tenth day, after removal of stitches. Externalisation of distal end of shunt with CSF drainage into a closed system was done in one infection episode where there was ventriculitis. A new shunt was inserted on the opposite side after the infection had subsided.

\section{DISCUSSION}

In this study, 107 infections were observed in 85 children with ventriculoperitoneal shunts for non tumour hydrocephalus between 1982 and 1991 at the Kenyatta National Hospital. Three hundred and forty five patients underwent V-P shunt placement for non-tumour hydrocephalus at the Kenyatta National Hospital during that period. The infection rate observed for V-P shunt placement was $24.6 \%$. This infection rate is high when compared with figures reported from centres in the Western World. However, it falls within the wide range of 0.0$38.0 \%$ that has been reported in the literature (4). A study carried out on post-operative wound infections at the Kenyatta National Hospital(5) found an infection rate of $26.3 \%$ complicating clean elective general surgical procedures, a rate which, although high is similar to the one reported in this study.

The relatively high rate of infection seen in patients undergoing V-P shunt surgery at the Kenyatta National Hospital may be related to hospital or theatre environment since a similar high rate of infection was reported in a previous study at the same institution on patients undergoing elective surgery (5). This high rate of infection is also similar to other rates of post surgical infection reported from other developing countries $(5,6)$.

Other factors which may contribute to the high rate of infection may be patient-related (for example, poor nutritional status, other concurrent infections). They may also be surgeon and theatre related. The relatively long ward-waiting time that most of the patients experienced before operation may also play a role in the high infection rate (5). This long pre-operative stay in the ward was due 
to factors such as a large patient work load, inability by the patient to afford a shunt immediately, unavailability of materials necessary for surgery and other similar problems found in the developing world. The male to female ratio of $1.3: 1$ observed in this study is probably a reflection of the general trend of male predominance in children with hydrocephalus undergoing shunt surgery (4,6-9).

The ages of the children in this study at the time of presentation with vetriculoperitoneal shunt infection are seen to range from three months to twelve years. The majority of the children were between three months and three years of age ( $82.4 \%)$. This may be due to the fact, that most of the children had hydrocephalus due to congenital causes. Studies done by other workers elsewhere show a similar pattern $(4,7,10,11)$. James(7), reported an age range of two months to 7.5 years in his patients with CSF shunt infections, while Quigley reported an age range of three months to 10 years with most of the patients being under one year(4). In this study most of the patients had shunts inserted at the age of less than one year with a peak age for shunt insertion at 3-4 months. This pattern is similar to that seen in other studies $(4,8)$ although in Puri's study (8) the peak age for shunt insertion was a little earlier at age two to three months.

The time interval from the onset of hydrocephalus or diagnosis of hydrocephalus to first shunt placement appears to be little reported in the literature. This time interval is of interest because it has a bearing on the neurological status of the child or brain damage that may occur before shunt surgery. Most of the patients in this study were found to have experienced a considerable delay before they could have shunt placement surgery. The delays were due to a number of reasons ranging from non-availability of shunts (patient's family unable to buy shunt) to the large number of patients awaiting surgery in the unit.

Although this study did not address the risk of developing shunt infection in relation to aetiology of hydrocephalus, other workers elsewhere have discussed this issue. Most workers have found no association between aetiology of hydrocephalus and shunt infection (9,11-15). Some have however found myelomeningocele to be a risk factor (16-18) while others have found intraventricular haemorrhage as a cause of hydrocephalus to be a major risk factor in shunt infection (4). Various reasons were given for the shunt revisions undertaken in this study prior to the development of shunt infection. Shunt block was the most common reason for shunt revision. Shunt blocks, which are a form of shunt malfunction, have been noted to be probably related to shunt infection in some studies $(6,10,22)$.

The role of other concurrent infections elsewhere in the body before or at the time of shunt surgery was reviewed by Renier (13) who found an association between the risk of shunt infection and upper respiratory tract infections. Concurrent infections were reported in $21.3 \%$ of patients presenting with infected V-P shunts in this study. However, other workers have found no correlation between the risk of shunt infection and other concurrent infections at the time of shunt surgery $(4,12,14,18)$. Anaemia and malnutrition reported in 13 of our patients (15.3\%) may have predisposed to infection by impairing the patients ability to resist infections. The highest bacterial isolation rate per type of specimen was from wound cultures (pus swabs). This is probably a reflection of the fact that cultures were done when there were obvious features of wound infection. A similar observation was made by Schoenbaum (11) who found $100 \%$ isolation rate from wound cultures. Removed shunts also showed a high isolation rate in this study. The low CSF bacterial isolation rate of $27.6 \%$ observed in this study is in sharp contrast to the CSF isolation rate of Schoenbaum(11) of $79 \%$. Staphylococcus aureus was the commonest organism isolated followed by coagulase negative staphylococci. This may be related to the fact that most of our isolates were from wounds. Bayston $(19,20,22)$ has observed that Staphylococcus aureus involvement in shunt infections appears to be more common in some units than others and their presence may be related to wound infections around the shunt rather than true shunt colonisation. Most of the infections in this study $(71 \%)$ were managed by removal of the infected shunt and placement of a new shunt. The practice of removal of an infected shunt followed by immediate shunt replacement at the same sitting has been tried by some workers $(7,21,23)$ with good results. However, when these results are compared with those where a shunt is reinserted after a period of treatment with antibiotics to control infection, the later option is found to be superior. This period of antibiotic therapy before shunt reinsertion is seen to be necessary to eradicate bacteria from the ventricles and peritoneal cavity(22). Bayston has recommended reinsertion of new shunts after a period of five and ten days of antibiotic therapy(22).

The difficulties in making diagnosis of shunt infection, and hence delayed shunt removal, has also been mentioned by Bayston(22). James(7) recommended reinsertion of a shunt after seven days of antibiotic therapy in patients who had their infected shunts removed. Many of the patients in this study experienced a delay before shunt reinsertion due to presence of infected wounds which took a long time to heal. Other reasons similar to those cited for initial shunt insertions like non availability of shunts also played a role in this delay. In conclusion, it has been observed in this study that the rate of infection in children undergoing ventriculoperitoneal shunt placement for hydrocephalus at the Kenyatta National Hospital was rather high. This high rate may be related to the surgical technique and theatre conditions at the time of surgery in addition to other patient related factors, such as, malnutrition, anaemia and prolonged pre-operative waiting period in the ward which would allow colonisation with hospital flora. The prolonged ward-waiting period may be due to theatre related factors and surgeonrelated factors. 


\section{ACKNOWLEDGEMENTS}

The Director, Kenyatta National Hospital and the Research and Ethics Committee, Kenyatta National Hospital, for permission to carry out this study and publish these findings.

\section{REFERENCES}

1. Davson, H., Welch, K. and Segal, M.B. Physiology and Pathophysiology of the cerebrospinal Fluid. Edinburgh, New York Churchill Living stone 1987.

2. Lyons, M.K. and Meyer, F.B. Cerebrospinal fluid physiology and the management of increased intracranial pressure. Mayo Clin. Proc. 1990; 65: 684 - 707.

3. Gaab, M.R. and Koos, W.T., Hydrocephalus in infancy and childhood; Diagnosis and indication for operation. Neuropaediatrics. 1984; 15: 173 - 179.

4. Quigley, M.R., Reigel, D.H. and Kortyana, R. Cerebrospinal fluid shunt infections. Report of 41 cases and critical review of the literature. Paediatric Neurosci. 1989; 15: 111 - 120.

5. Masiira-Mukasa; Post operative wound sepsis in general surgical wards at the Kenyatta National Hospital Master of Medicine (Surgery) Dissertation 1981, University of Nairobi.

6. Gichuki, M.K. complications of ventriculoperitoneal shunts in management of congenital and acquired hydrocephalus as seen at Kenyatta National Hospital. Master of Medicine (Surgery) dissertation 1989, University of Nairobi.

7. James, H.E., Walsh, J.W., Wilson HD., Connor J.D., Bean, J.R. Tibbs, P.A., Prospective randomised study of therapy in cerebrospinal fluid shunt infection. Neurosurgery 1980; 7: 459 - 463 .

8. Puri, P., Malone, M. and Guiney E.J., Primary hydrocephalus, the effect of timing of first valve insertion, valve revision and the nature of revisions on intelligence 2. Kinderchir 1977; 22: 506510.

9. Schmidt, K., Gjeris, F., Osgaard, O., Hvidberg, E.F., Kristiansen, J.E., Dahlerup, B., KruseLarsen, C. Antibiotic psophylaxis in cerebrospinal fluid shunting; A prospective randomized trial in 152 hydrocephalus patients. Neurosurgery 1985; 17: 1-5.

10. George, R., Liebrock, L., Epstein M., Long term analysis of cerebrospinal fluid shunt infections. A 25 year experience. $J$. Neurosurgery 1979; 5: 804 - 811.

11. Schoenbaum, S.C., Gardner, P. and Shillito J; Infections of cerebrospinal fluid shunts: Epidemiology, clinical manifestations and therapy. J. Infect. Dis. 1975; 131: 543 - 552.

12. Haines, S. and Taylor, F. Prophylactic methicillin for shunt operations; effects on incidence of shunt malfunction and infection. Child's Brain 1982; 9: 10 - 22.

13. Renier, D., Lacombe, J., Pierre-Kahnn, A., Sainte-Rose, C. and Hirsch J., Factors causing acute shunt infections: A computer analysis of 1174 operations J. Neurosurg. 1984; 61: 1072 1078.

14. Shapiro, S., Boaz, J., Kleimas, M., Kalsbeck, J., Mealey, J., Origin of organisms infecting ventrucular shunts. Neurosurg. 1988; 22: 868 - 872,

15. Walters, B.C., Hoffman, H.J., Hendrick, E.B. and Humphreys, R.P; Decreased risk of infection in cerebrospinal fluid shunt surgery using prophylactic antibiotics. A case control study. $Z$. Kinderchir 1985; 40: 15 - 18

16. McCullough, D.C., Kane, J.G., Presper, J.H. and Wells, M. Antibiotic prophylaxis in vetricular shunt surgery. Reduction of operative infection rates with methicillin. Child's Brain 1980; 7: 182 - 189.

17. Odio, C., McCracken, G.H. and Nelson J. CSF Shunt infections in paediatrics. A seven year experience. A.M. J. Dis. Chil. 1984; 138: $1103-1108$

18. Shurtleff, D.B., Christie, D. and Foltz, E.L., ventriculo auriculostomy- associated infection: a 12 year study. $J$. Neurosurg. 1971; 35: 686 - 694.

19. Bayston, R. CSF Shunt infections by coagulase - Negative staphylococci. ZbI Bakt. Supp. 1987; 16: 133- 142.

20. Bayston, R. and Spitz, L. Infective and systemic causes of malfunction of ventriculo peritoneal shunts for hydrocephalus. Z. Kinderchir 1977; 22: 419 - 424.

21. O'Brien, M., Parent, A. and David, B; Management of vitricular shunt infections. Child's Brain 1979; 5: 304-309.

22. Bayston, R; Hydrocephalus shunt infections and their treatment. J. Antimicrob. Chemotherap. 1985; 15: 259 - 261.

23. Oerrin, J.C.S., Mclaurin, R.L. Infected ventriculoatrial shunts. A method of treatment. J. Neurosurg. 1967; 27: 21 - 26. 